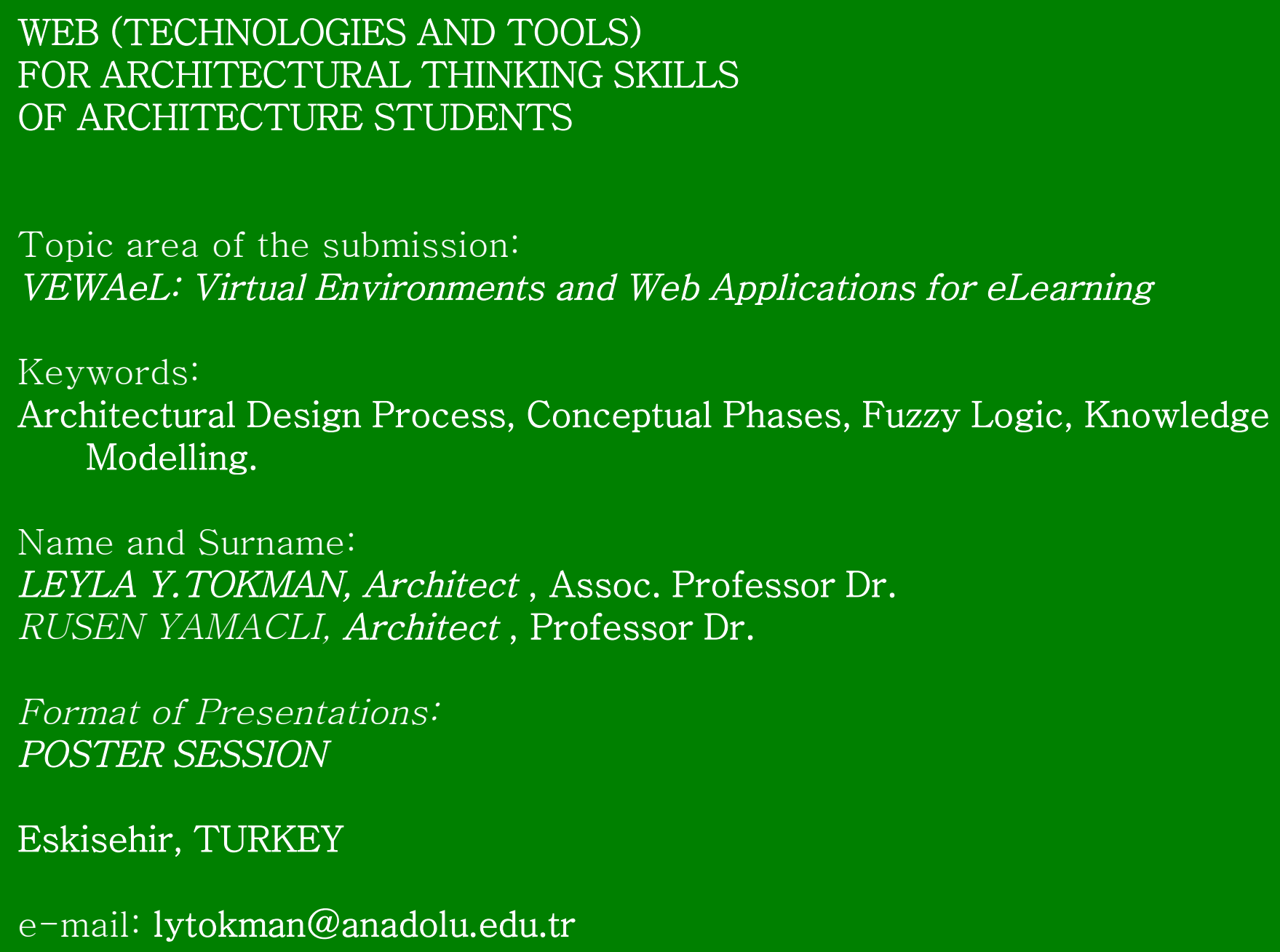


The Fourth International Conference on Internet Monitoring and Protection, ICIMP 2009, May 24-28, 2009 - Venice, Italy

"VEWAeL: Virtual Environments and Web Applications for eLearning", http://www.iaria.org/conferences2009/ICIMP09.html

\section{WEB (TECHNOLOGIES AND TOOLS) FOR ARCHITECTURAL THINKING SKILLS OF ARCHITECTURE STUDENTS}

\section{ABSTRACT}

Architectural design is a combination of various disciplines and subtopics of architecture due to its broad area of study and great amount of knowledge it covers. These complex relationships should be considered together, therefore architectural design covers a process which aims to reach an optimal solution. Which method/techniques should be applied while teaching this complex process to students who have just been introduced to architectural design? With regard this question, there has been some research on to what extent web technology and tools (especially artificial intelligence/fuzzy logic and online study) can have an effective role in finding a solution to this problem.

Keywords - architectural design process, conceptual phases, knowledge modeling

\section{ARCHITECTURAL THINKING PATTERN}

This study deals with developing a flow logic for "an architectural design process" on students, which was designed on the basis of the methods being applied in architectural design studios according to architectural thinking pattern. This model was applied in L.Y.Tokman's class in Design courses. The some courses are prepared and taught in collaboration with the researcher's colleague R. Yamacli. The topic of this research paper was the source of the research "Knowledge Modeling for Conceptual Architectural Design Phases" by L.Y.Tokman. The case study based on library buildings. This research study, still developing, focused also on how web technology and tools can be used to support this method in different early phases of the process. Green buildings and energy efficient design are also other two main points of the study. Developing idea Modeling for Conceptual Architectural Design Phases" is still improving for educational standards 


\section{The developing system consists of four major components:}

a) Design Engine on web

It generates an e-library of ecology and building design (theory_ fundamental design knowledge, using all the features of the multimedia audio, video, images, game _puzzles and links_reference libraries, component libraries, accessing helpful links related to design etc. )

b) Design Development Tool

A user could select, change, share and visualize designs on virtual environments. Meanwhile the architectural design process consists of goals, solutions and alternatives to reach the goals, and design knowledge. Besides that, the interactivity of virtual environments and data transmission are as important as imaginative design developments.

c) Software

d) Web Technologies \& Tools

Communication and presentation skills (these skills such as ability to enter/update e-mail and other communication data, ability to use search tools, download and upload skills, sharing data, presenting data, storing data and CADcompatible documentation usage are essential skills for users). 
The Fourth International Conference on Internet Monitoring and Protection, ICIMP 2009, May 24-28, 2009 - Venice, Italy

"VEWAeL: Virtual Environments and Web Applications for eLearning", http://www.iaria.org/conferences2009/ICIMP09.html

\section{WEB (TECHNOLOGIES AND TOOLS) FOR ARCHITECTURAL THINKING SKILLS OF ARCHITECTURE STUDENTS}

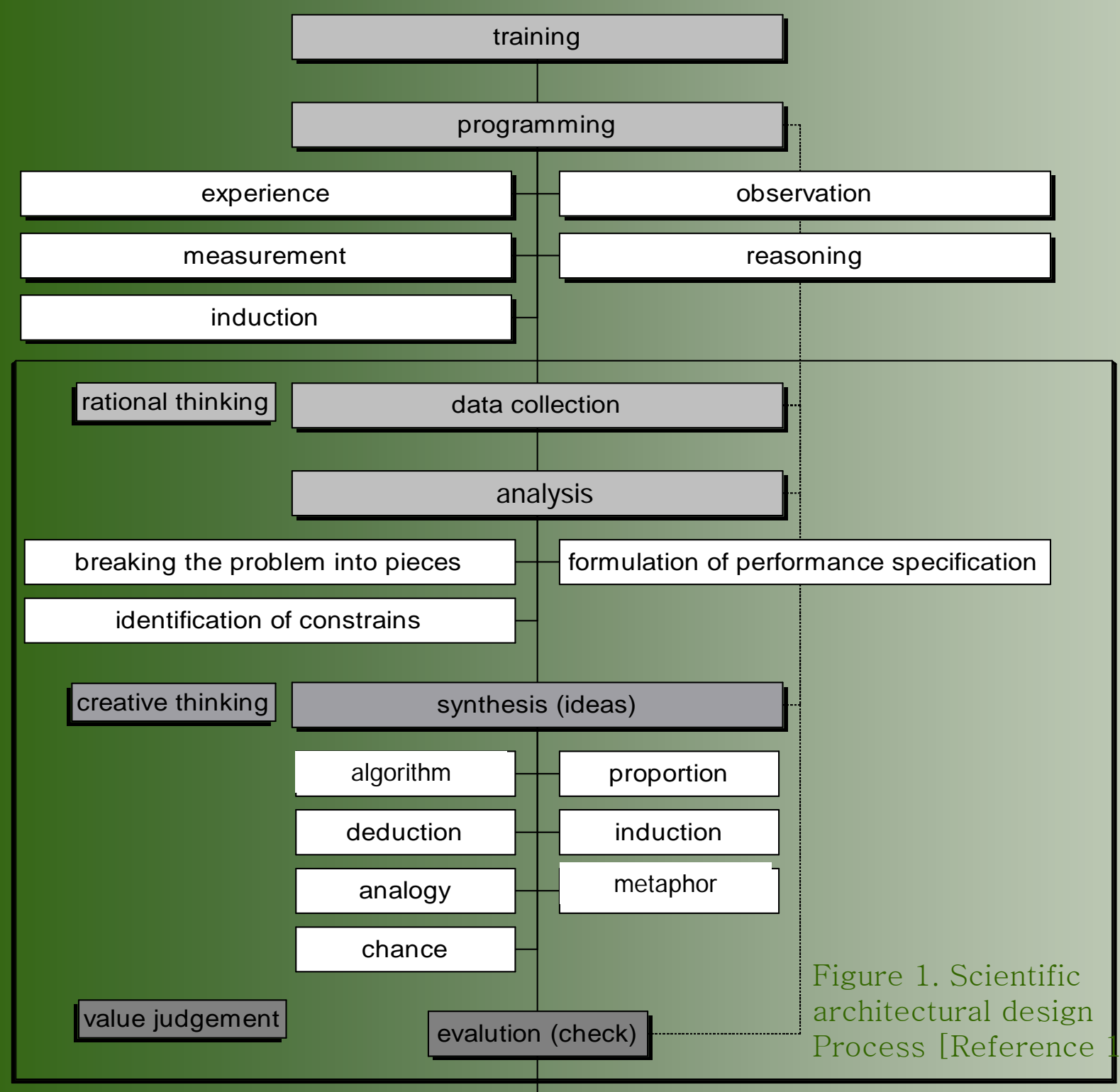

Objectives for conceptual phase of architectural design process

1) To actively aware of architectural thinking: first, translating the examples into the space and form making.

2) To actively concerned the architectural systems: the building and environmental systems

3) To actively aware of basic architectural design knowledge as an thinking activity

4) To actively aware of the architectural design process: to discover the loops of data

5) To actively develop knowledge and skills on the essential tools of design including analyzing (rational thinking) and synthesis (creative thinking) data and then evalution (value judgement) as well as using CAD and WEB technologies and tools for design development (figure 1 and figure 2)

6) To actively explore the relationship between architectural space and ergonomics. 
The Fourth International Conference on Internet Monitoring and Protection, ICIMP 2009, May 24-28, 2009 - Venice, Italy "VEWAeL: Virtual Environments and Web Applications for eLearning", http://www.iaria.org/conferences2009/ICIMP09.html

\section{WEB (TECHNOLOGIES AND TOOLS) FOR ARCHITECTURAL THINKING SKILLS OF ARCHITECTURE STUDENTS}
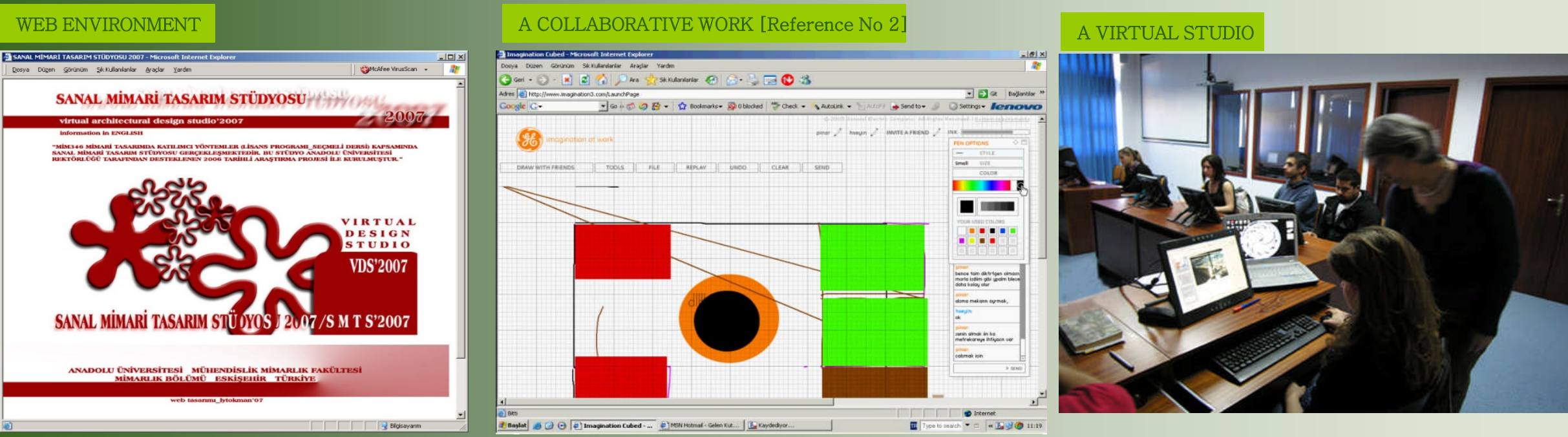

\section{CONCLUSION}

The aim of the computer-aided (the software and web environment) support is to enable students to: 1) to define the design problem on web environment: photos, CAD files etc.

2) to share the files and to produce solutions, alternatives with the other students on-line

3) to understand the collaborative design process.

4) to share architecture design critics

5) to chose the best alternative solution

6) to develop a collaborative design approach on web (understanding web technologies and tools). These experimental studies can bring data over ICT communication and transfer the data into knowledge in conceptual phases of architectural design. The virtual environment will enable the students to upload and download files, collaborative study, presentation and to get critics in the web environment. The goal of web tools and technologies in this virtual environment is to encourage collaborative design / presentation works between students and to encourage sharing ICT knowledge and techniques in group studies. The results obtained from each project reflect an experience and continuity for next one in $\mathrm{e}^{-}$-studio environment. 
The Fourth International Conference on Internet Monitoring and Protection, ICIMP 2009, May 24-28, 2009 - Venice, Italy

\section{REFERENCES}

[1] Archer's model,

Francis Bacon, Quinton, (Oxford.Oxford University Press, 1980)

Rene A. Descartes, A Discourse On Method, tr. by John Veitch;

intrtod. A.D. Lindsay, (London : J.M. Dent \& Sons Ltd. ; New York :

E.P. Dutton \& Co Inc., 1953.)

Carl G., Hemple, Philosophy of Natural Science, (NJ.: Prentice Hall, Englewood Cliffs, 1966)

Alan F. Chalmers, What is This Thing Called Science? An Assesment of The Nature and Status of Science And its Methods, (St Lucia,

Brisbane: University of Queensland Press, 3rd Edition, 1999)

Geoffrey Broadbent, Design In Architecture: Architecture and Human

Sciences, (Chichester, UK: Jhon Wiley and Sons,1973)

Peter G. Rowe, Design Thinking, (Cambridge, Massachusetts; London, England: The MIT Press, 1987), pp:50-80.

[2] General Electric Company, 2005-2008, http://www.imaginationcubed.com/

All photographs were taken by the authors.

\section{THANK YOU}

